\title{
Comparative Studies on the Behaviour of Flat Panels Made of GRP Under Static and Dynamic Loads
}

\author{
COSTEL IULIAN MOCANU ${ }^{1 *}$, ALIN POHILCA ${ }^{1}$, LIVIU MOISE ${ }^{1}$, \\ DANIELA IOANA TUDOSE ${ }^{2}$ \\ ${ }^{1}$ Dunarea de Jos University, 47 Domneasca Str., 800008, Galati, Romania \\ ${ }^{2}$ Politehnica University of Bucharest, 313 Splaiul Independentei, 060042, Bucharest, Romania
}

\begin{abstract}
Glass reinforced plastic, so called GRP, is a composite material made of glass strands called fibbers woven together to create a flexible fabric. GRP is a lightweight material with many and diverse applications ranging from the manufacture of reservoirs for different liquids to the manufacture of boats, yachts, chairs and even children playground furniture. The behaviour of this material under static and dynamic loads is still raising interest from the scientific community and a large number of researchers. This continued interest is due to the material versatility for different applications depending on its manufacture process that has a significant weigh-in in the material mechanical properties. These resulting mechanical properties need to be carefully analysed and benchmarked prior to using the obtained material in commercial applications. The scope of this research study is to analyse the behaviour of glass reinforced plastic plate panel with reinforcements on one and two directions under static and dynamic loads employing both experimental and numerical methods for results validation. The methods used in this research study for the dynamic loads can also be applied successfully to other composite materials. Additionally, the stress plots have been analysed in iteration in order to ensure the most optimal reinforcement pattern.
\end{abstract}

Keywords: electrical resistive tensometry, strain, stress, displacement, FEM

\section{Introduction}

Composite materials are obtained by combining two or more base materials. The mechanical properties of the parent materials are combined resulting in a superior material with enhanced mechanical properties. The method of moulding two or more materials proves efficient in replacing one base material deficiencies with the other base material superior properties. The method provides the possibility of programming the composite material mechanical properties from the concept stage, resulting in a final material net superior to the base materials with applications in the aerospace industry, car manufacturing, etc. [1,2].

Similarly, these composite materials are used on a large scale in the shipbuilding industry $[3,4]$. Shipbuilders are always looking to improve their traditional shipbuilding methods and to replace the materials used, such as steel, with better performing materials. To this date, GRP has been successfully used for the construction of leisure boats, rapidly becoming the standard material used in this sector [5, 6].Due to the fact that composite materials are diamagnetic, they are also applicable for warships (Figure 1), and medium sized yachts up to $67 \mathrm{~m}$ length (Figure 2), etc.

Another important advantage manifested by the usage of composite materials in shipbuilding relates to low maintenance costs compared to steel for instance. These costs are drastically reduced, as observed from the exploitation of these boats, which lead to GRP being the preferred material of choice for a range of boats as indicated in the paragraph above [7,8].

The behaviour of steel and other traditional materials is well documented, especially the behaviour under static and dynamic loads. The current study presents the research carried out for the comparative analysis of GRP reinforced plate panels under the same type of loads. The precision degree of the method employed in this study recommends this approach as being one of the most suited methods to describe the mechanical properties of composite materials [9].

\footnotetext{
*email: costel.mocanu@ugal.ro
} 


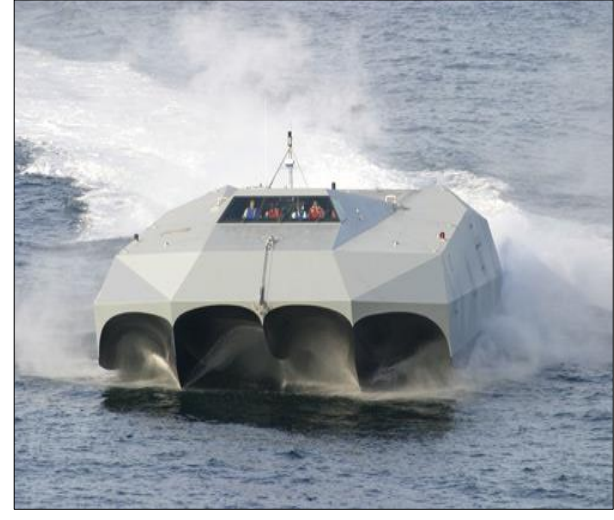

Figure 1. Warship

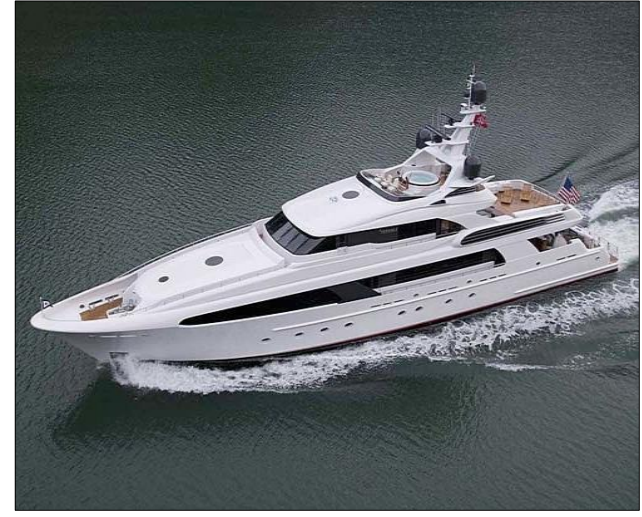

Figure 2. Yacht

Another important advantage manifested by the usage of composite materials in shipbuilding relates to low maintenance costs compared to steel for instance. These costs are drastically reduced, as observed from the exploitation of these boats, which lead to GRP being the preferred material of choice for a range of boats as indicated in the paragraph above [7, 8].

The behaviour of steel and other traditional materials is well documented, especially the behaviour under static and dynamic loads. The current study presents the research carried out for the comparative analysis of GRP reinforced plate panels under the same type of loads. The precision degree of the method employed in this study recommends this approach as being one of the most suited methods to describe the mechanical properties of composite materials [9].

The analysis has been carried on several specimens of free plane plate panels (Figure 3) and reinforced plane plate panels with reinforcements on two directions (Figure 4). The experiments carried out and the numerical analysis are carried for both static and dynamic loads $[5,10,11]$.

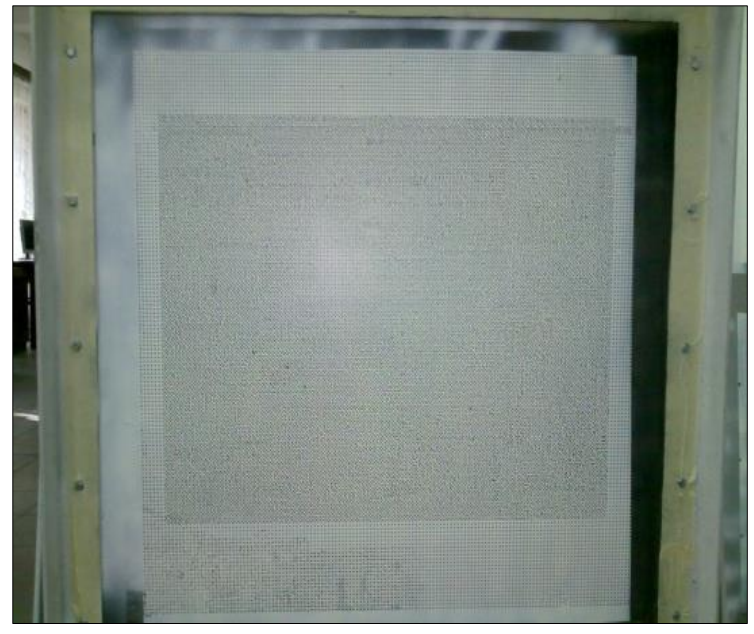

Figure 3. Free plane plate panel

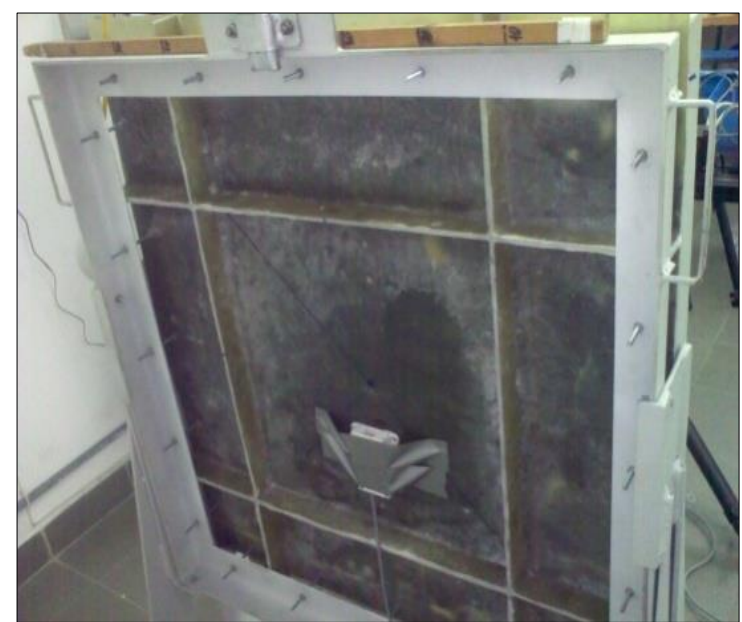

Figure 4. Reinforced plane plate panel

\section{Materials and methods}

\subsection{Static numerical analysis and experimental research of free and reinforced plane plate panels made of GRP}

Electrical resistive tensometry (TER) has been employed for the experimental phase used to determine the stress-strain behaviour of the plane plate specimens. As a short description, TER methodology is based on the electrical resistance variation of a loaded metallic wire which is electrically live. The metallic wire is placed on a support that provides electrical isolation, and the whole ensemble constitutes the tensometric strain gauge sensor. The tensometric strain gauge sensors have a particular 
shape (Figure 5), have minimal dimensions $(15 \mathrm{~mm} \times 5 \mathrm{~mm})$ and require a simple method of application, usually they are glued to the surface of the specimen [12].

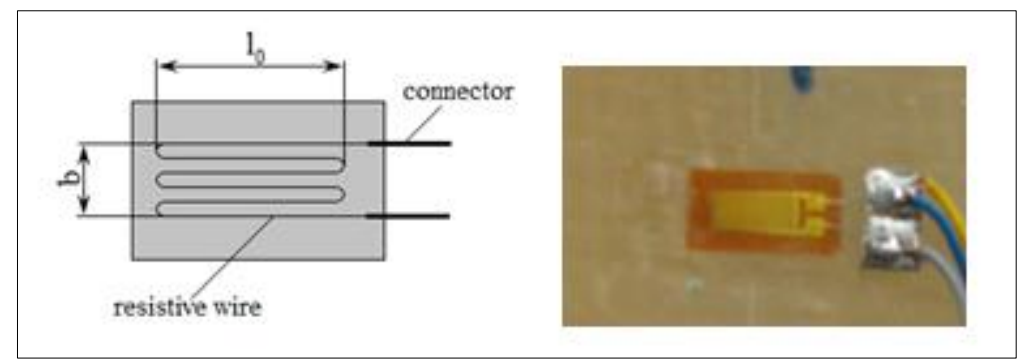

Figure 5. Tensometric strain gauge sensor

The tensometric strain gauge sensor is glued to the specimen surface allowing it to detect the smallest deformation of the surface recorded by a variation of its electric resistance. The electrical resistance variation of the sensor by the mechanical surface deformation is the definition of TER method.

Using this method, TER, the plate specimens stress behaviour has been carried analysis. Several measurement points have been established and tensometric strain gauge sensor have been applied accordingly. The type of the sensors used, HBM 1-LY11-10/120, have a measurement base length of 10 $\mathrm{mm}$ and an electrical resistance of $120 \Omega$.

In order to record the variation of the electrical signal, a data acquisition system, SPIDER8, provided by same manufacturer of the strain gauge sensors. has been used. The experimental setup (Figure 6) is made of: data acquisition system SPIDER 8 (1), laptop with Catman Express 3.1 software [12] (2), GRP plane plate panel (3) reinforced with a steel rim to simulate fully fixed boundary conditions, tensometric strain gauge sensors, (4), test load (5) and connecting tensometric wires (6). On a case by case approach and experience, the number of strain gauge sensors has been established, 6 for the free plane plate panel and 5 for the reinforced plane plate panel.

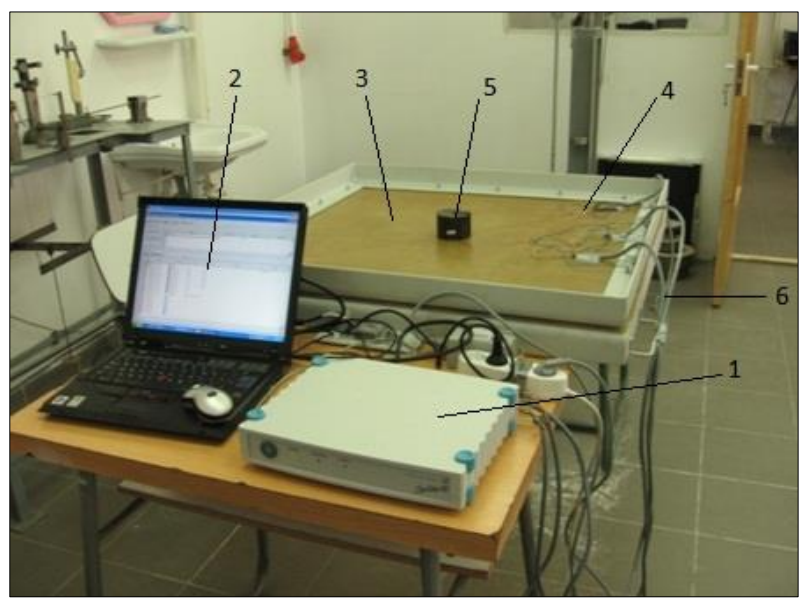

Figure 6. The experimental test stand used

Numerically, the static analysis has been carried out using the Finite Element Method and the dedicated Cosmos software. The coordinate system of the model in Cosmos has been matched and aligned with the experimental specimen in order to easily extract stress and strain values on the same direction as the strain gauges sensors local coordinate system (Figure 7 and 8).

\subsubsection{Experimental tests - free plane plate field}

For this case, the plane plate field without reinforcements or open as it has been named previously, the strain gauge sensors have been placed as represented in Figure 7. 
The recommended practice is to prepare the plate surface prior to gluing the strain gauges sensors.

Strain gauge sensor number 2 and number 4 are positioned accordingly for recording values in the Ox direction and strain gauge sensors number 1 and 3 for recording values on the Oy direction. Strain gauge sensors number 5 and 6 are placed at a $45^{\circ}$ angle with respect to $\mathrm{O} x$.

The static loading procedure has been completed using calibrated weights that were placed in the centre of the free plane plate field (Figure 7). The loading was made in ascending order increasing the object weight from $0 \mathrm{~N}$ to $65 \mathrm{~N}$ and respectively in descending order from $65 \mathrm{~N}$ to $0 \mathrm{~N}$. The recorded strain measurements have been used to determine the stress values using Hookes's law, together with the experimental determination of the longitudinal elasticity modulus, which on average yielded the value $E=1,884 \cdot 10^{9} \mathrm{~Pa}$.

$$
\sigma_{\text {mes }}=E \cdot \varepsilon_{\text {mes }} \cdot 10^{-5}[\mathrm{~Pa}]
$$

(the $10^{-5}$ represents the amplification factor required for the scaling of the recorded values using the Spider 8 data acquisition system)

These results are centralized in Table 1.

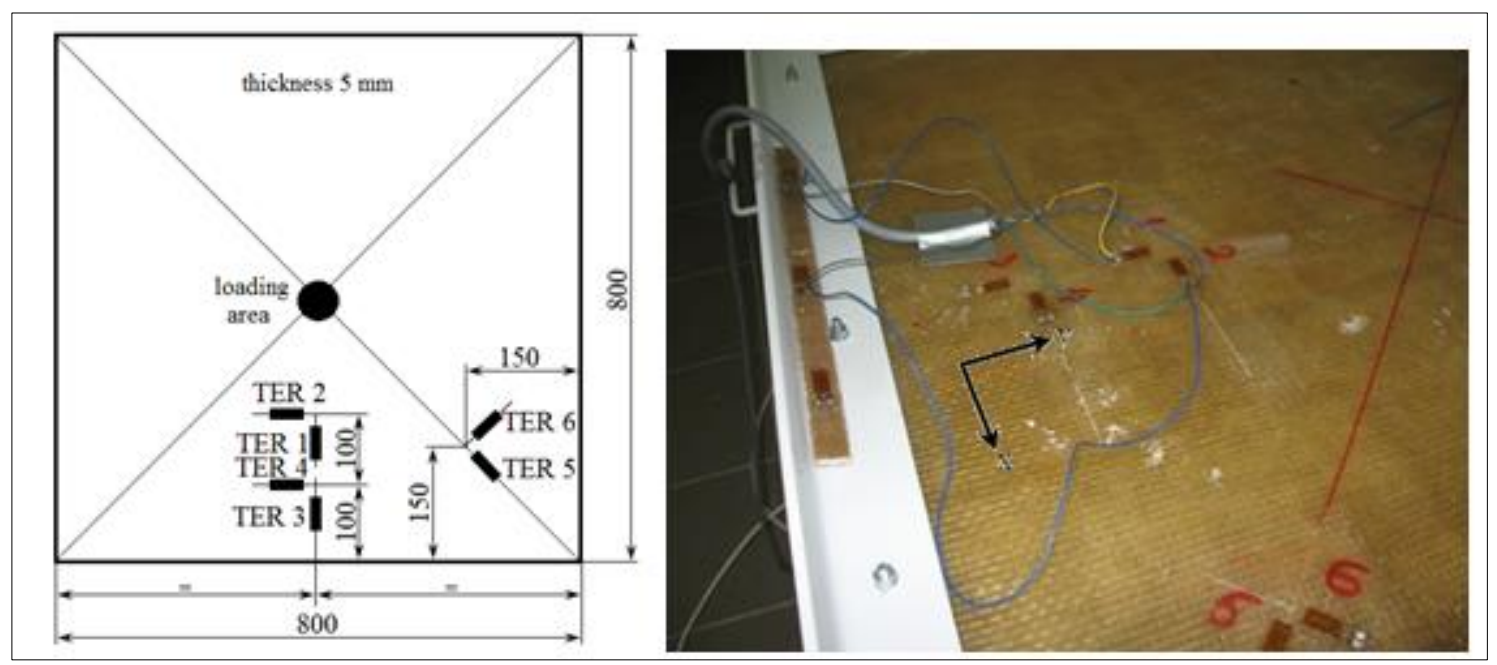

Figure 7. Free plane plated field experimental setup

Table 1. Recorded strain values - $O x, O y$ directions

\begin{tabular}{|c|c|c|c|c|c|c|}
\hline Load & $\operatorname{Tr} 1$ (Oy) & $\operatorname{Tr} 2(\mathbf{O x})$ & $\operatorname{Tr} 3(O y)$ & $\operatorname{Tr} 4(\mathbf{O x})$ & $\operatorname{Tr} 5$ & $\operatorname{Tr} 6$ \\
\hline$[\mathbf{N}]$ & \multicolumn{6}{|c|}{$[\mu \mathbf{m} / \mathbf{m}]$} \\
\hline 0 & 0.00 & 0.00 & 0.00 & 0.00 & 0.00 & 0.00 \\
\hline 5 & 7.40 & 21.39 & 10.94 & 26.18 & 10.44 & 6.93 \\
\hline 15 & 22.20 & 64.18 & 32.83 & 78.54 & 31.31 & 20.80 \\
\hline 35 & 51.79 & 149.76 & 76.60 & 183.26 & 73.05 & 48.54 \\
\hline 65 & 96.18 & 278.13 & 142.25 & 340.34 & 135.67 & 90.15 \\
\hline 35 & 61.77 & 178.62 & 91.35 & 218.57 & 87.13 & 57.89 \\
\hline 15 & 30.38 & 87.84 & 44.93 & 107.49 & 42.85 & 28.47 \\
\hline 5 & 9.80 & 28.34 & 14.49 & 34.67 & 13.82 & 9.18 \\
\hline 0 & 3.16 & 9.14 & 4.68 & 11.19 & 4.46 & 2.96 \\
\hline
\end{tabular}

\subsubsection{Numerical analysis - free plane plate field}

The numerical analysis carried out using FEM and Cosmos used SHELL 4T elements (elements with 4 nodes and 3 DOF per node, one translation and two rotations). The boundary conditions used were fixed conditions, while the load has been applied as a surface uniform load matching the exact surface 
contact area of the experimental calibrated weights to accurately replicate the experiment conditions. It must be noted that the material used in the numerical analysis is isotropic, having the same mechanical properties in all directions. It is considered that this hypothesis is acceptable, as using orthotropic or anisotropic materials will substantially increase computational times with little added precision to results obtained. The results obtained have an error of calculation under $10 \%[1,13]$.

The model has 3200 elements and 1681 nodes and it replicated as much as possible the experimental setup. The modelled GRP panels has been fixed on all four sides and the loading force has been applied in the centre of the free plate field with a normal force of $65 \mathrm{~N}$ (Figure 8).

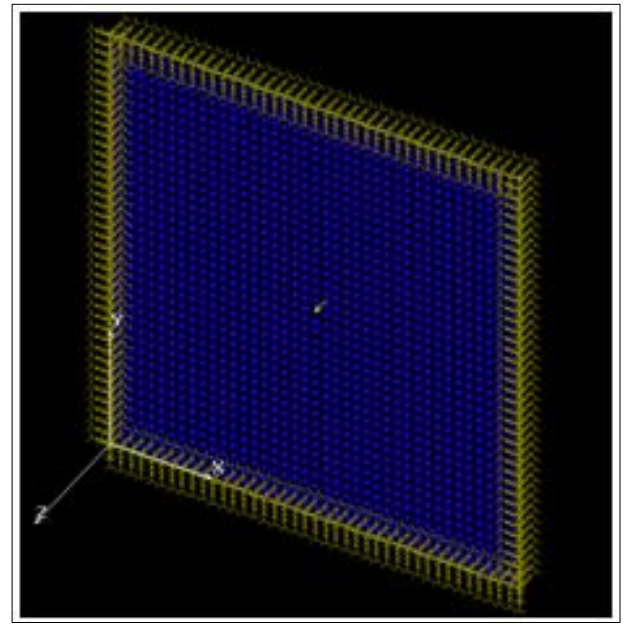

Figure 8. Loads and boundary conditions used in numerical analysis

In the below figures, the von Mises stress plot and displacement plots are presented for one of the loading conditions, with the load variation following the experimental values, from 0 to $65 \mathrm{~N}$ (Figure 9 and 10).

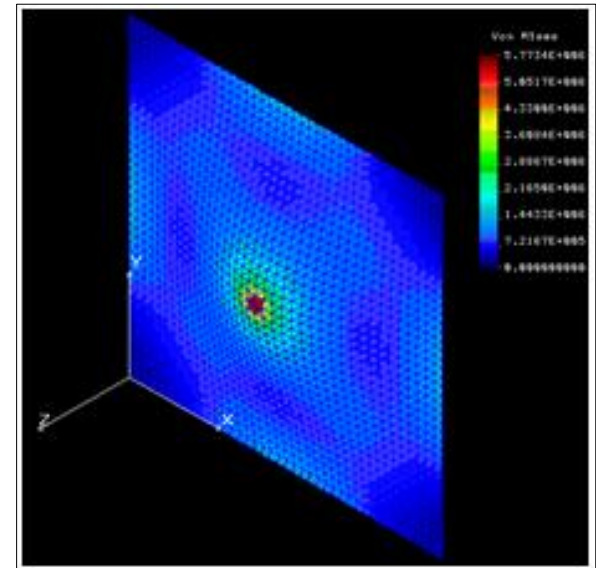

Figure 9. von Mises Stress

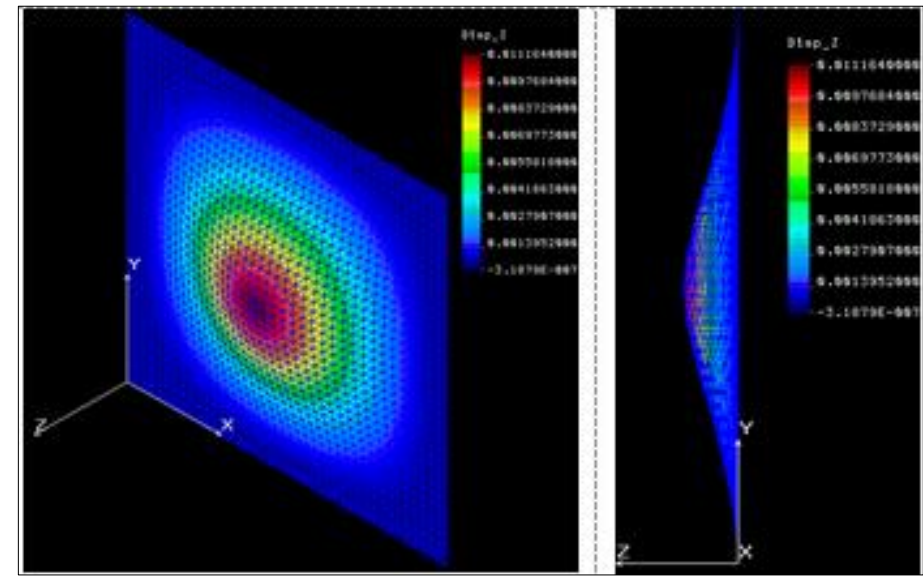

Figure 10. Displacements

The results from both the experiment and the numerical analysis have been compared accordingly in the interest areas (the locations of the strain gauge sensors has been paired between the two situations) and the values recorded for the maximum load case, $65 \mathrm{~N}$, are presented in Table 2. Maximum deviation of $5.71 \%$ has been obtained for $\operatorname{Tr} 4$ location.

Figure 11 shows graphically the difference between the measured and calculated values for the $65 \mathrm{~N}$ load case. 


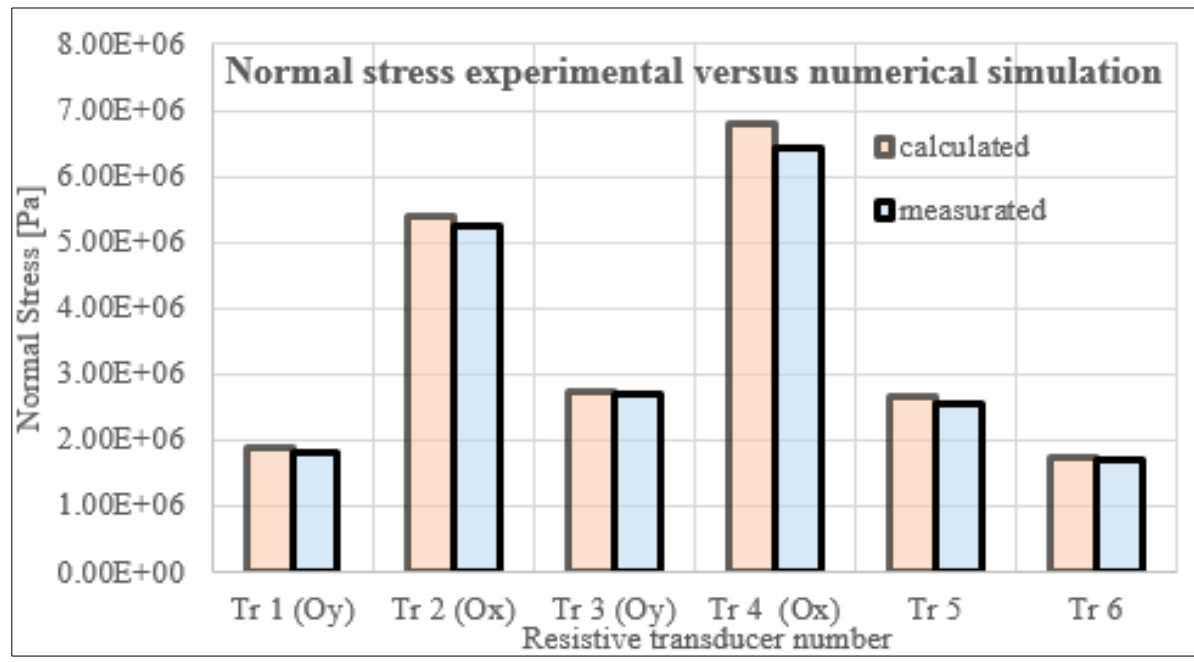

Figure 11. Comparison between stress value measured and calculated

Table 2. Comparison between measured and calculated normal stress

\begin{tabular}{|c|c|c|c|c|c|c|}
\hline \multicolumn{7}{|c|}{ Measured } \\
\hline \multirow{2}{*}{$\frac{\text { Load }}{[N]}$} & $\operatorname{Tr} 1(O y)$ & $\operatorname{Tr} 2(\mathbf{O x})$ & $\operatorname{Tr} 3(0 y)$ & $\operatorname{Tr} 4(0 x)$ & $\operatorname{Tr} 5$ & $\operatorname{Tr} 6$ \\
\hline & \multicolumn{6}{|c|}{ Normal stress [Pa] } \\
\hline \multirow{3}{*}{65} & $1.81 \mathrm{E}+06$ & $5.24 \mathrm{E}+06$ & $2.68 \mathrm{E}+06$ & $6.41 \mathrm{E}+06$ & $2.56 \mathrm{E}+06$ & $1.70 \mathrm{E}+06$ \\
\hline & \multicolumn{6}{|c|}{ Specific strain $[\mu \mathrm{m} / \mathrm{m}]$} \\
\hline & 96.48 & 278.13 & 142.25 & 340.34 & 135.67 & 90.15 \\
\hline \multicolumn{7}{|c|}{ Calculated } \\
\hline Load / Nod & Nod Tr 1 & Nod Tr 2 & Nod Tr 3 & Nod $\operatorname{Tr} 4$ & Nod Tr 5 & Nod Tr 6 \\
\hline NOD & 854 & 659 & 699 & 740 & 1203 & 1282 \\
\hline$[N]$ & \multicolumn{6}{|c|}{ Normal stress $[\mathrm{Pa}]$} \\
\hline \multirow{3}{*}{65} & $1.89 \mathrm{E}+06$ & $5.40 \mathrm{E}+06$ & $2.73 E+06$ & $6.80 \mathrm{E}+06$ & $2.67 \mathrm{E}+06$ & $1.74 \mathrm{E}+06$ \\
\hline & \multicolumn{6}{|c|}{ Specific strain $[\mu \mathrm{m} / \mathrm{m}]$} \\
\hline & 100.16 & 286.73 & 144.96 & 360.83 & 141.51 & 92.52 \\
\hline \multicolumn{7}{|c|}{ Errors } \\
\hline Normal Stress & $4.13 \%$ & $2.96 \%$ & $1.83 \%$ & $5.71 \%$ & $4.27 \%$ & $2.93 \%$ \\
\hline
\end{tabular}

\subsubsection{Experimental tests - reinforced plane plate field}

The same equipment and strain gauge sensors have been used in this case also. Two strain gauge sensors have been applied on the panel reinforcements, at a $90^{\circ}$ offset (Figure 12) in order to record the reinforcement behaviour during the loading procedure.
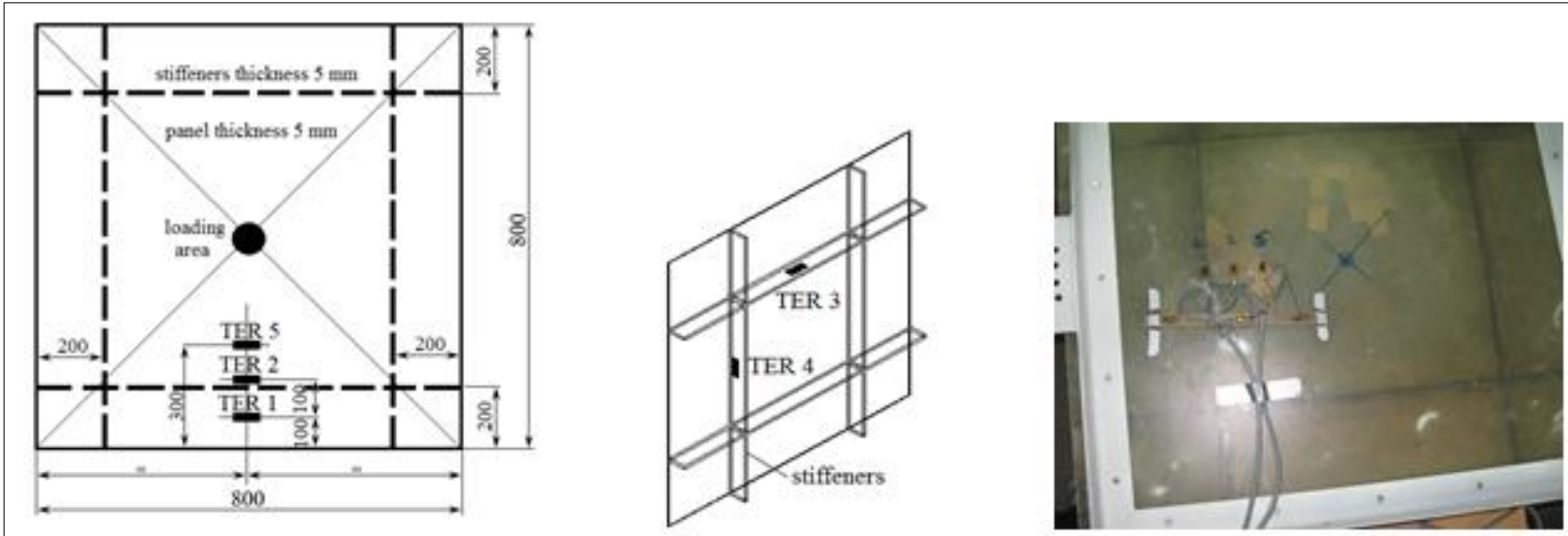

Figure 12. Panel front and back sketc 
The experimental procedure has been repeated as for the free plane plate specimen. The centralized results are presented in Table 3.

Table 3. Measured normal stress and strain values - $O x$ and $O y$

\begin{tabular}{|c|c|c|c|c|c|}
\hline Load & $\operatorname{Tr} \mathbf{1}(\mathbf{O x})$ & $\operatorname{Tr} \mathbf{2}(\mathbf{O x})$ & $\operatorname{Tr} \mathbf{3}$ & $\operatorname{Tr} \mathbf{4}$ & $\operatorname{Tr} \mathbf{5}(\mathbf{O x})$ \\
\hline$[\mathrm{N}]$ & {$[\mu \mathrm{m} / \mathrm{m}]$} & {$[\mu \mathrm{m} / \mathrm{m}]$} & {$[\mu \mathrm{m} / \mathrm{m}]$} & {$[\mu \mathrm{m} / \mathrm{m}]$} & {$[\mu \mathrm{m} / \mathrm{m}]$} \\
\hline 0 & 0.00 & 0.00 & 0.00 & 0.00 & 0.00 \\
\hline 5 & 3.35 & 4.09 & 15.49 & 16.35 & 4.65 \\
\hline 15 & 13.39 & 16.37 & 61.98 & 65.39 & 18.60 \\
\hline 35 & 41.51 & 50.74 & 192.14 & 202.72 & 57.66 \\
\hline $\mathbf{6 5}$ & $\mathbf{9 5 . 4 7}$ & $\mathbf{1 1 6 . 7 0}$ & $\mathbf{4 4 1 . 9 2}$ & $\mathbf{4 6 6 . 2 5}$ & $\mathbf{1 3 2 . 6 3}$ \\
\hline 35 & 40.63 & 49.66 & 188.05 & 198.40 & 56.44 \\
\hline 15 & 13.32 & 16.28 & 61.66 & 65.05 & 18.50 \\
\hline 5 & 3.42 & 4.17 & 15.81 & 16.68 & 4.74 \\
\hline 0 & 0.70 & 0.51 & -0.22 & 0.54 & 0.21 \\
\hline
\end{tabular}

\subsubsection{Numerical analysis - reinforced plane plate field}

Similarly, to the free plane plate model, the FEM has been employed, and the specimen has been modelled in CosmosM [14]. The modelling has been performed using SHELL 4T elements (elements with 4 nodes and 3 DOF per node, one translation and two rotations). The model is made of 2400 elements and 2481 nodes, as shown in Figure 13. A similar comparison as for the free plane plate panel has been made, presenting the recorded values for the experiment and the numerical analysis in the same geometrical locations where the strain gauge sensors have been applied. The results are presented in Table 4.

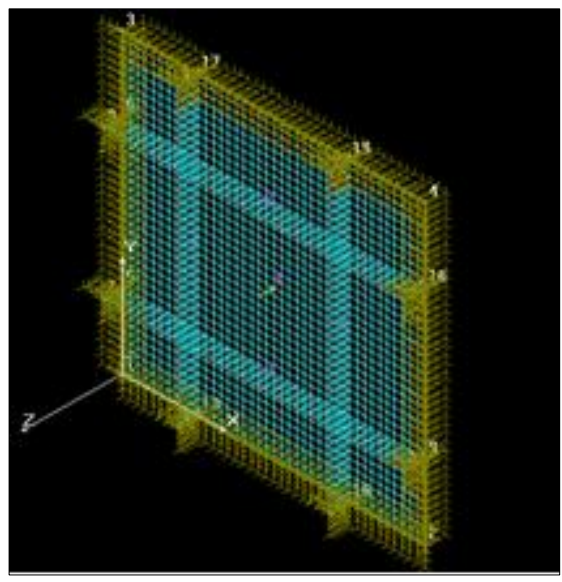

Figure 13. Panel discretisation

In the Figure 14, 15, the von Mises stress plot and displacement plots are presented for one of the loading conditions, with the load variation following the experimental values, from 0 to $65 \mathrm{~N}$.

The results from both the experiment and the numerical analysis have been compared accordingly in the interest areas (the locations of the strain gauge sensors has been paired between the two situations) and the values recorded for the maximum load case, $65 \mathrm{~N}$, are presented in Figure 16 and Table 4. Maximum deviation of $6.05 \%$ has been obtained for $\operatorname{Tr} 5$ location. 


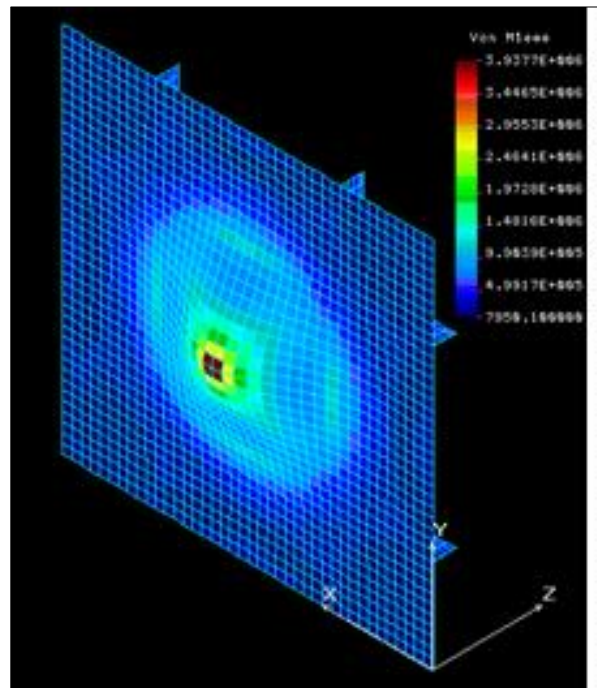

Figure 14. von Mises stress
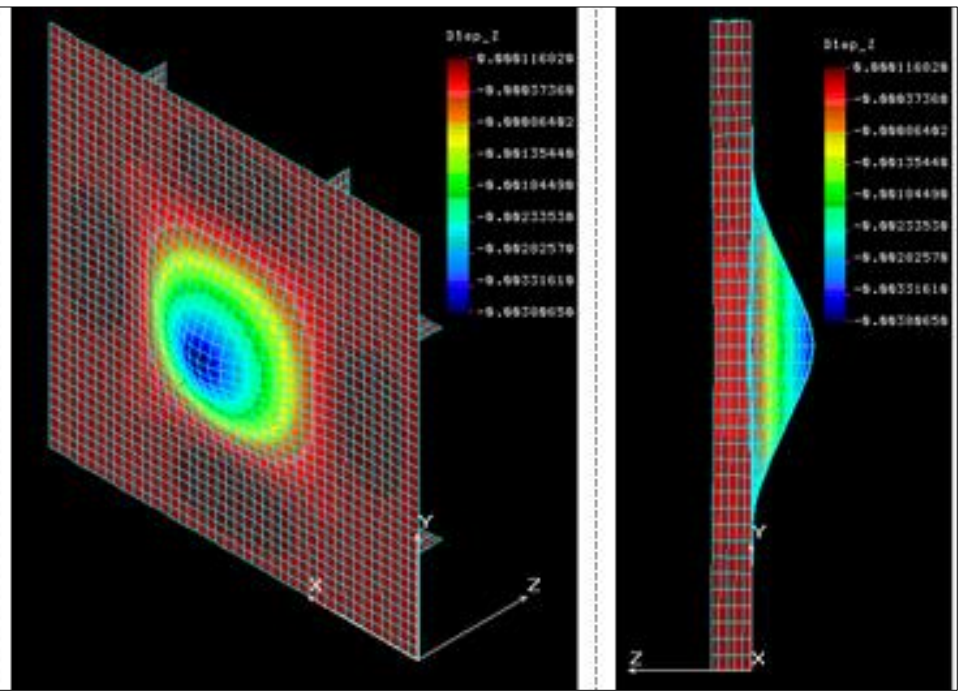

Figure 15. Displacements

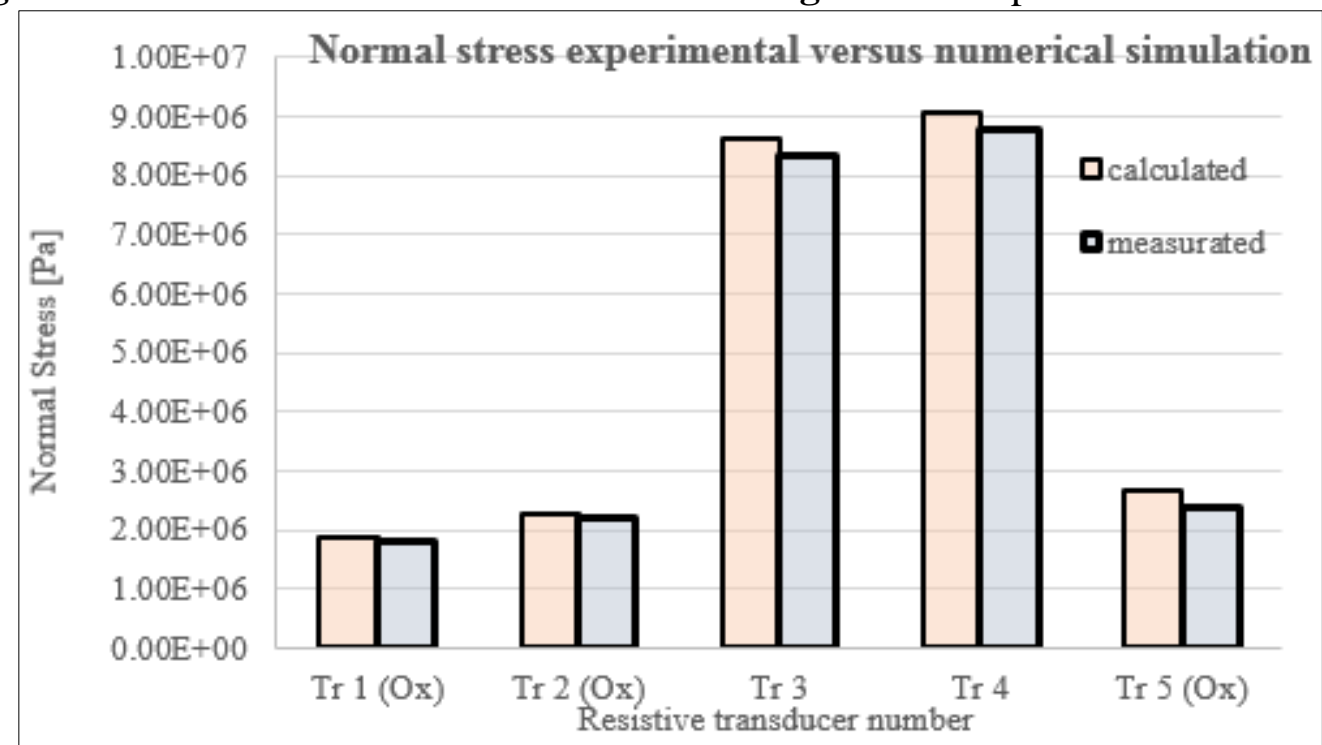

Figure 16. Comparison between stress value measured and calculated

Table 4. Comparison between measured and calculated normal stress

\begin{tabular}{|c|c|c|c|c|c|}
\hline \multicolumn{6}{|c|}{ Measured } \\
\hline Load & $\operatorname{Tr} 1(\mathbf{O x})$ & $\operatorname{Tr} 2(\mathrm{Ox})$ & $\operatorname{Tr} 3$ & $\operatorname{Tr} 4$ & $\operatorname{Tr} 5(O x)$ \\
\hline$[N]$ & \multicolumn{5}{|c|}{ Normal stress [Pa] } \\
\hline \multirow{3}{*}{65} & $1.80 \mathrm{E}+06$ & $2.20 \mathrm{E}+06$ & $8.33 E+06$ & $8.78 E+06$ & $2.50 \mathrm{E}+06$ \\
\hline & \multicolumn{5}{|c|}{ Specific strain $[\mu \mathrm{m} / \mathrm{m}]$} \\
\hline & 95.47 & 116.70 & 441.92 & 466.25 & 125.73 \\
\hline \multicolumn{6}{|c|}{ Calculated } \\
\hline Load / Nod & Nod Tr 1 & Nod Tr 2 & Nod Tr 3 & Nod $\operatorname{Tr} 4$ & Nod Tr 5 \\
\hline NOD & 854 & 659 & 699 & 740 & 1203 \\
\hline$[N]$ & \multicolumn{5}{|c|}{ Normal stress [Pa] } \\
\hline \multirow{3}{*}{65} & $1.89 \mathrm{E}+06$ & $2.28 \mathrm{E}+06$ & $8.61 \mathrm{E}+06$ & $9.06 \mathrm{E}+06$ & $2.66 \mathrm{E}+06$ \\
\hline & \multicolumn{5}{|c|}{ Specific strain $[\mu \mathrm{m} / \mathrm{m}]$} \\
\hline & 100.53 & 120.91 & 457.22 & 480.94 & 141.10 \\
\hline \multicolumn{6}{|c|}{ Errors \% } \\
\hline Normal Stress & $5.03 \%$ & $3.48 \%$ & $3.35 \%$ & $3.06 \%$ & $6.01 \%$ \\
\hline
\end{tabular}

\subsection{Experimental and numerical analysis for the GRP reinforced plane plate panel [14]}


A dynamic analysis is required in order to investigate, especially for leisure boats, several types of possible impact during operation of these vessels, such as wave impact, slamming, or impact with a floating or underwater object. Large displacements determined by these dynamic loads can cause local structural failures and also, most importantly they can cause the GRP gel coat to get damaged which can lead to substantial deterioration of the vessel hull. In this study, the dynamic analysis results shall focus on the values of displacements obtained under such loading conditions [14]. The dynamic analyses (experimental and numerical) have been performed on the same type of specimens as for the static analysis.

\subsubsection{Experimental dynamic analysis - free and reinforced GRP panel}

The experimental dynamic analysis has been performed on the GRP specimens using an innovative optical (no contact) system, ARAMIS HS, supplied by a the company GOM Germany [15]. This optical system is able to measure any deformations that are developed during the tests of the GRP specimens, by using two high speed and high-resolution cameras. The camera system are able to provide results by surprising and measuring the displacements of a grid system which must be attached to the GRP specimen prior to the analysis.

In summary, the ARAMIS HS system has the following way of work:

- The camera system is able to map the surface of the GRP specimen and to allocate a local coordinate system that will help map all the points of the grid drawn on the specimen and consequently of every pixel of the frame recorded.

- The initial snapshot, frame zero, is the static reference (no deformations of the free plane plate panel) that will be used as a benchmark for the following snapshots taken during the entire procedure.

- The following frames are recorded during the loading of the specimen and using photogrammetry and dedicated software all the image pixels receive a set of coordinates that are compared with the static references, frame zero, which in turn allows us determine the specimen deformations.

With the aid of this innovative system, a range of various analyses can be performed such as creep analysis and components ageing process, benchmark analysis by comparing with FEM models, determination of composite material mechanical properties, strain calculations, etc

The presented research is particularly important in understanding the behaviour of GRP specimens during impact loads that have been simulated during the experiment and numerical modelling in two main phases:

1) Phase 1 - Applying the grid on the experiment specimens, which consists in the imprinting of small round dots on the GRP surface. This can be done either via spraying black paint on top of a specifically manufactured metallic template applied to the GRP specimen or by applying a specially manufactured membrane (Figure 17). The maximum diameter of the grid points is not larger than $2 \mathrm{~mm}$. This stage is crucial for the quality of results obtained, because the grid is using to calibrate the system and subsequently to measure all the distances travelled by each of these dots (which are matched with pixels in the frames recorded by the system) in order to calculate displacements and deformations.

2) Optical system and sensor calibration is performed using a special device, the calibration cross which is supplied by the manufacturer (Figure 18). This device comes in two sizes, depending on the size of the specimen to be analysed [15].

Finally, after the tested GRP specimen has been prepared and the correct grid has been laid out and the system has been calibrated, the working setup is as per Figure 19. 


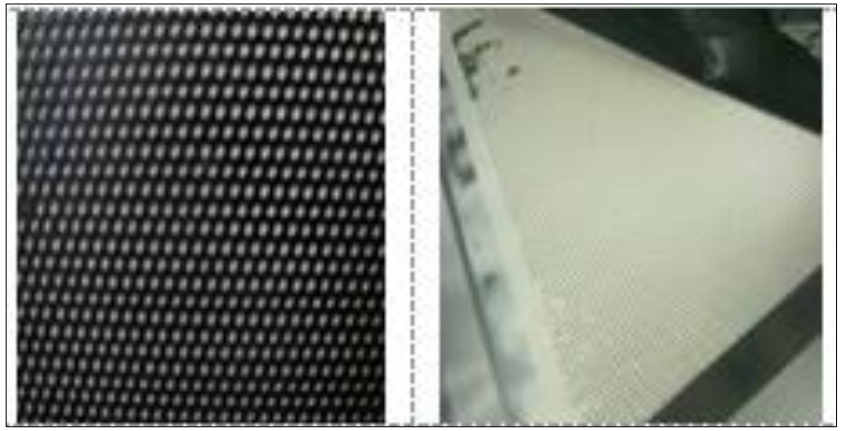

Figure 17. Metallic template or special membrane for applying the grid on the specimens

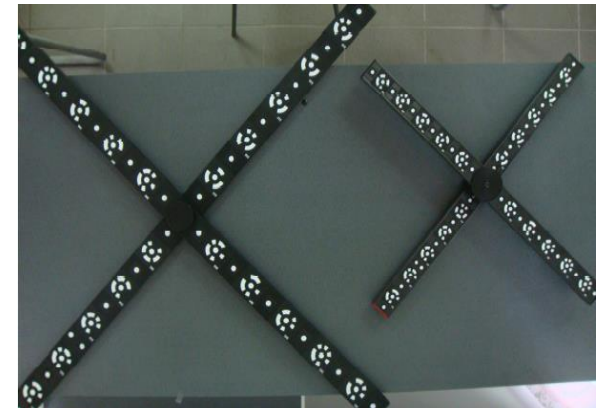

Figure 18. Calibration device for the optical system

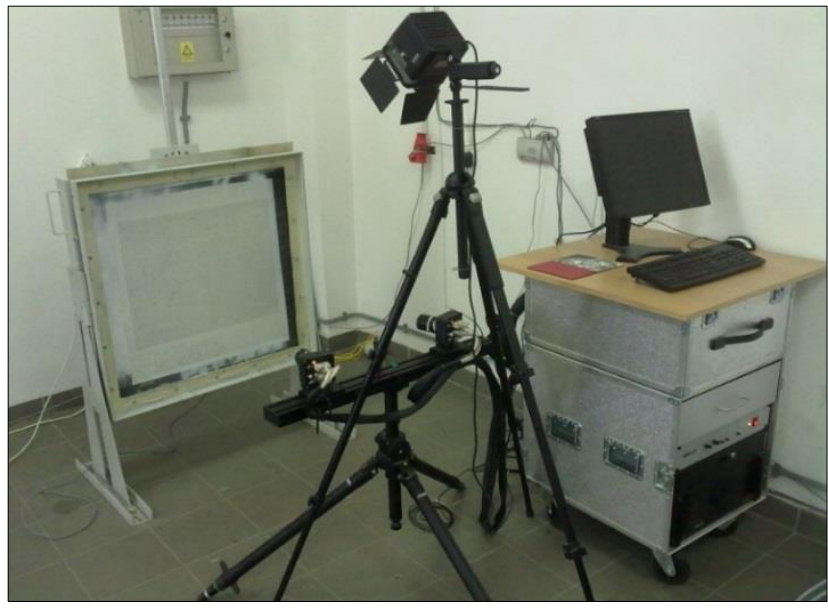

Figure 19. Measurement system

The dynamic loading of the GRP specimens has been performed using a simple pendulum system, composed of a round ball (mass $4.07 \mathrm{~kg}$ ) and a flexible wire (length of $900 \mathrm{~mm}$ ) Figure 20.

Both GRP panels have been under the same loading conditions in order to have solid understanding while comparing the results obtained. Keeping the loading pattern constant, it was possible to understand the structural contribution of the reinforcements during the dynamic analysis. Two types of loads have been used as a variation of the distance $d(200 \mathrm{~mm}$ and $400 \mathrm{~mm})$, which is the horizontal distance measured from the surface of the GRP specimen to the point of the round ball release position. The impact forces obtained in this manner have been determined using the gravitational pendulum theory and are presented in Table 5.

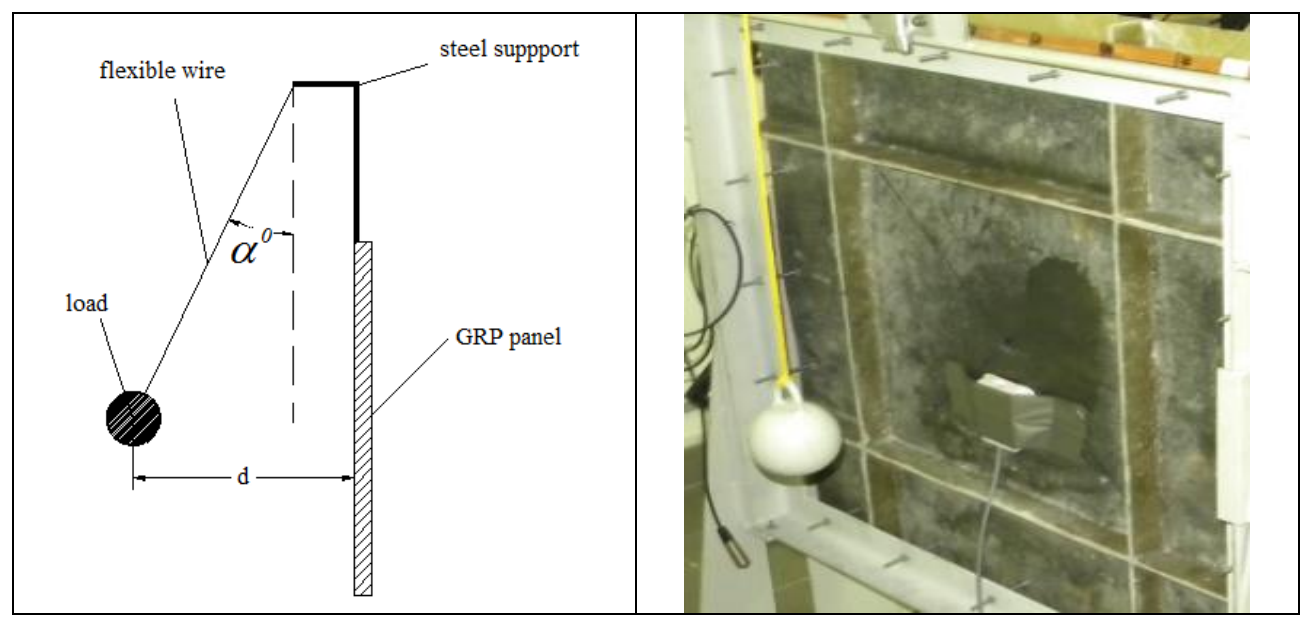

Figure 20. The dynamic loading of the GRP specimens 
Table 5. Load data

\begin{tabular}{|c|c|c|c|c|c|c|}
\hline Panel Type & $\mathbf{D},[\mathbf{m m}]$ & $\boldsymbol{\alpha}^{\mathbf{0}}$ & Impact Force, [N] & Impact time, [s] & Impact Mass, [kg] & Wire Length, [mm] \\
\hline Free panel & 200 & 12.73 & 9.04 & \multirow{2}{*}{0.0575} & 4.07 & 900 \\
\hline $\begin{array}{c}\text { Reinforced } \\
\text { panel }\end{array}$ & 400 & 25.46 & 18.08 & 0.05 & \\
\hline
\end{tabular}

The dynamic analysis, performed with the help of the optical system, is made by the recording of the two panels behaviour starting from frame zero (before impact), during impact and after the impact load. The frames recorded have been used to determine maxim deformations and displacements on all 3 directions ( $\mathrm{x}, \mathrm{y}$ and $\mathrm{z}$ ). The frame recording speed is 400 frame / $\mathrm{s}$ and the exposure time is $1 \mathrm{~s}$.

All the results are presented as follows. In the Figure 21 is presented displacements plot for the load case 1 and in the Figure 23 is presented displacements plot for the load case 2. Figures 22, 24 shows the evolution of the displacements in time.

LOAD CASE $1, \mathrm{~d}=200 \mathrm{~mm}$
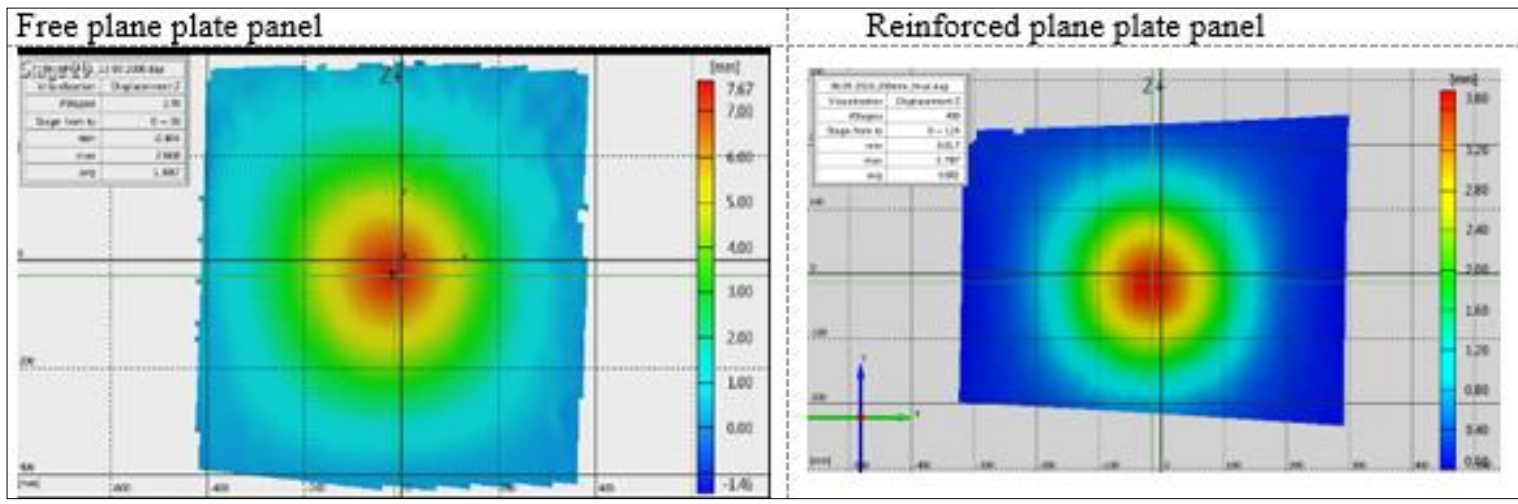

Figure 21. Displacements
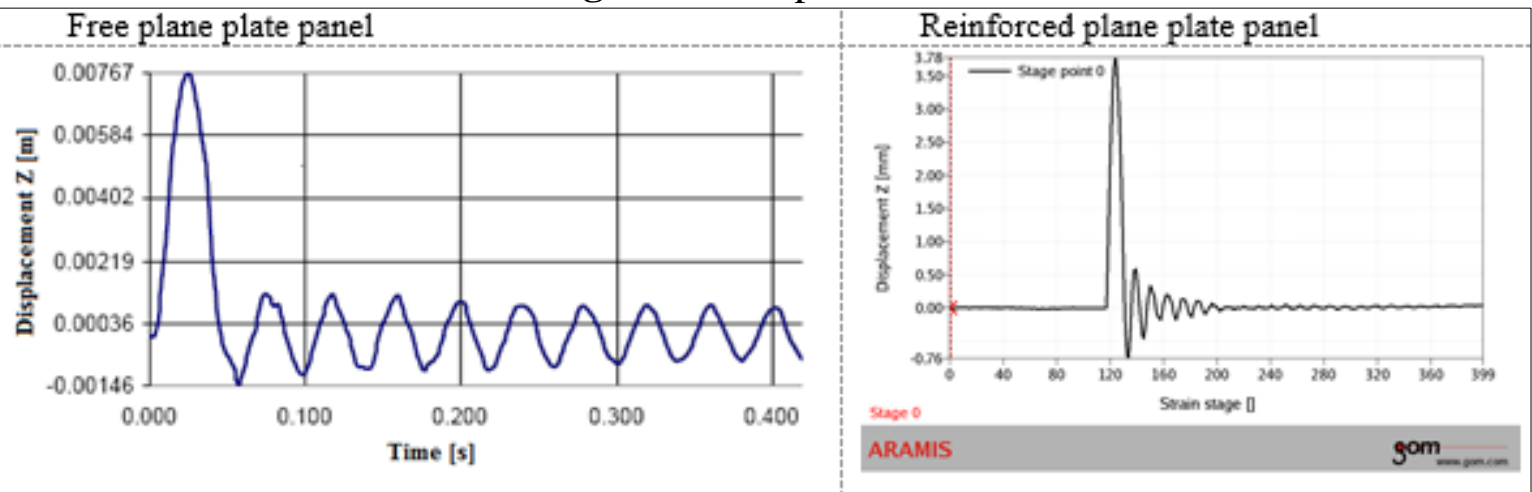

Figure 22. Displacement recorded as a function of time LOAD CASE 2, d=400 mm

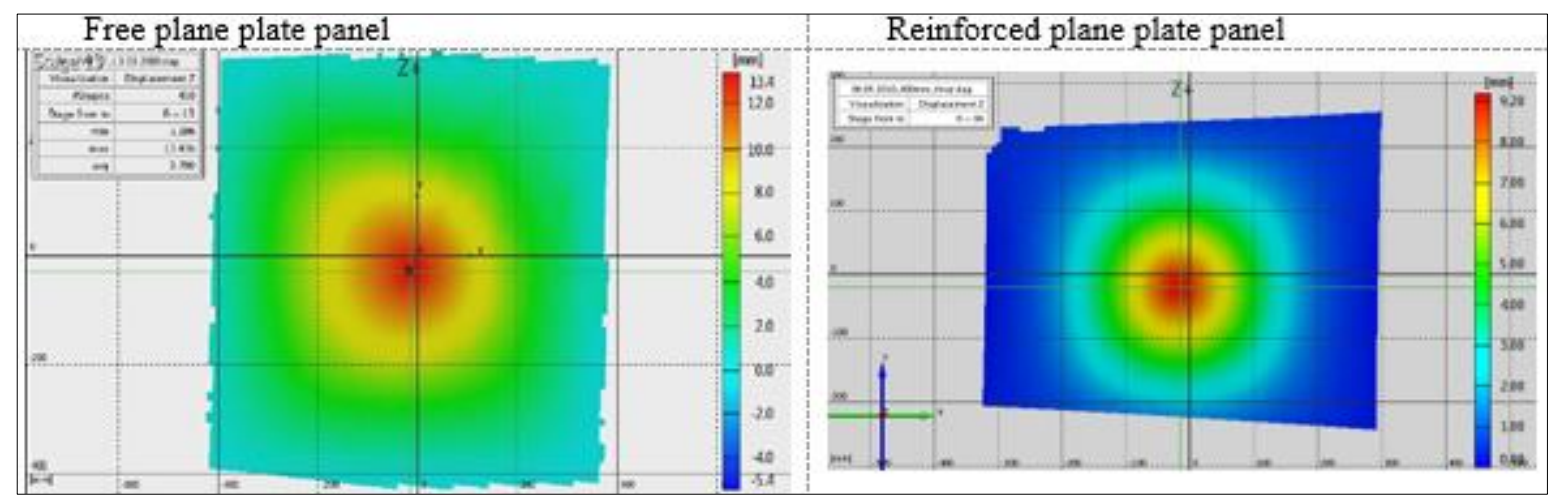

Figure 23. Displacements 
In Figure 21 (at time $t_{\text {impact }}$ ), the maximum values for the displacements on the normal direction are presented. These values are:

- maximum deformation for the free plane plate panel is $d_{\max }=7.67 \mathrm{~mm}$;

- maximum deformation for the reinforced plane plate panel is $d_{\max }=3.78 \mathrm{~mm}$.

Similarly, to case 2, in Figure 23 (at time $t_{\text {impact}}$ ), the maximum values for the displacements on the normal direction are presented. These values are:

- maximum deformation for the free plane plate panel is $d_{\max }=13.4 \mathrm{~mm}$;

- maximum deformation for the reinforced plane plate panel is $d_{\max }=9.1 \mathrm{~mm}$.
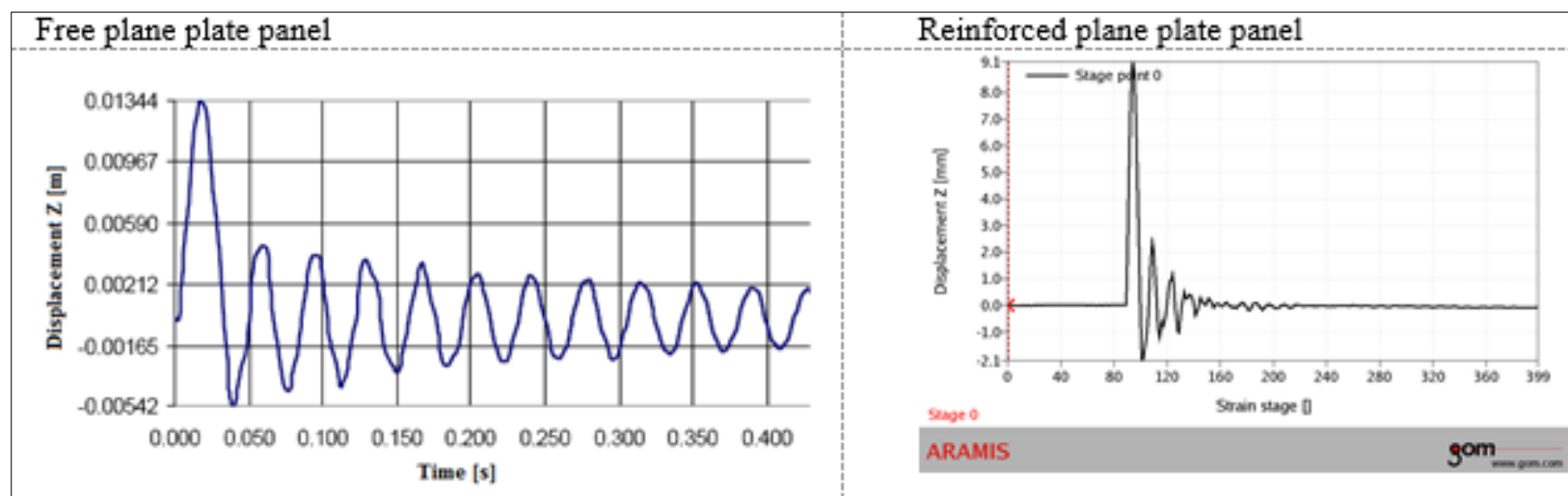

Figure 24. Displacement recorded as a function of time

\subsubsection{Numerical analysis - free and reinforced GRP panel}

The numerical analysis has been carried similarly to the static analysis, the only difference being the variation of the loading force, as per values presented in Table 5. Maximum recorded displacements are presented in Table 6.

Table 6. Maximum displacements for free and reinforced GRP plane plate panel under dynamic loads - Experiment vs Numerical analysis

\begin{tabular}{|c|c|c|}
\hline \multicolumn{2}{|c|}{ Maximum displacement measured [mm] } \\
\hline Load [N] & $\begin{array}{c}\text { Without } \\
\text { stiffeners }\end{array}$ & With stiffeners \\
\hline 9.04 & 7.67 & 3.78 \\
\hline 18.08 & 13.4 & 9.1 \\
\hline Maximum displacement calculated [mm] \\
\hline \multicolumn{3}{|c|}{ Panel type } \\
\hline Load [N] & $\begin{array}{c}\text { Without } \\
\text { stiffeners }\end{array}$ & With stiffeners \\
\hline 9.04 & 8.12 & 3.95 \\
\hline 18.08 & 14.2 & 9.75 \\
\hline \multicolumn{3}{|c|}{ Errors } \\
\hline Load [N] & $5.54 \%$ & $4.30 \%$ \\
\hline 9.04 & $5.63 \%$ & $6.67 \%$ \\
\hline 18.08 & \multicolumn{2}{|c|}{} \\
\hline \multicolumn{3}{|c|}{} \\
\hline
\end{tabular}

The maximum error obtained between the two methods is calculated below $10 \%$. 


\section{Results and discussions}

All results (normal tensions after $O x$ and $O y$ ) for the experimental procedure and the numerical analysis for both types of GRP panels have been centralized in Table 7.

\subsection{Static analysis for the free and reinforced GRP panel}

The following conclusions can be drawn:

1. All deviations presented in Table 8 for the free GRP panel are within the accepted limits in mechanical engineering procedures. This shows that the experimental analysis validates the numerical analysis. Additionally, the level of result deviations obtained also proves that the GRP material can be analysed as an isotropic material. All the mechanical characteristic which are obtained via the experiment can be used with trust in the numerical analysis.

2. The pattern of the measured deformations and the normal tensions proves to be linear on $O x$ and Oy direction $O x, O y$ (Figure 25). This proves that the composite material, in the experimental conditions described has a linear elastic behaviour (Table 3).

Table 7. Deviations between results obtained via experimental procedure and numerical analysis for the free plane plate panel - under $65 \mathrm{~N}$ load

\begin{tabular}{|c|c|c|c|c|c|c|}
\hline & $\operatorname{Tr} \mathbf{1}(\mathbf{O y})$ & $\operatorname{Tr} \mathbf{2}(\mathbf{O x})$ & $\operatorname{Tr} \mathbf{3}(\mathbf{O y})$ & $\operatorname{Tr} \mathbf{4}(\mathbf{O x})$ & $\operatorname{Tr} \mathbf{5}$ & $\operatorname{Tr} \mathbf{6}$ \\
\hline $\begin{array}{c}\text { Normal } \\
\text { Stress }\end{array}$ & $4.13 \%$ & $2.96 \%$ & $1.83 \%$ & $5.71 \%$ & $4.27 \%$ & $2.93 \%$ \\
\hline
\end{tabular}

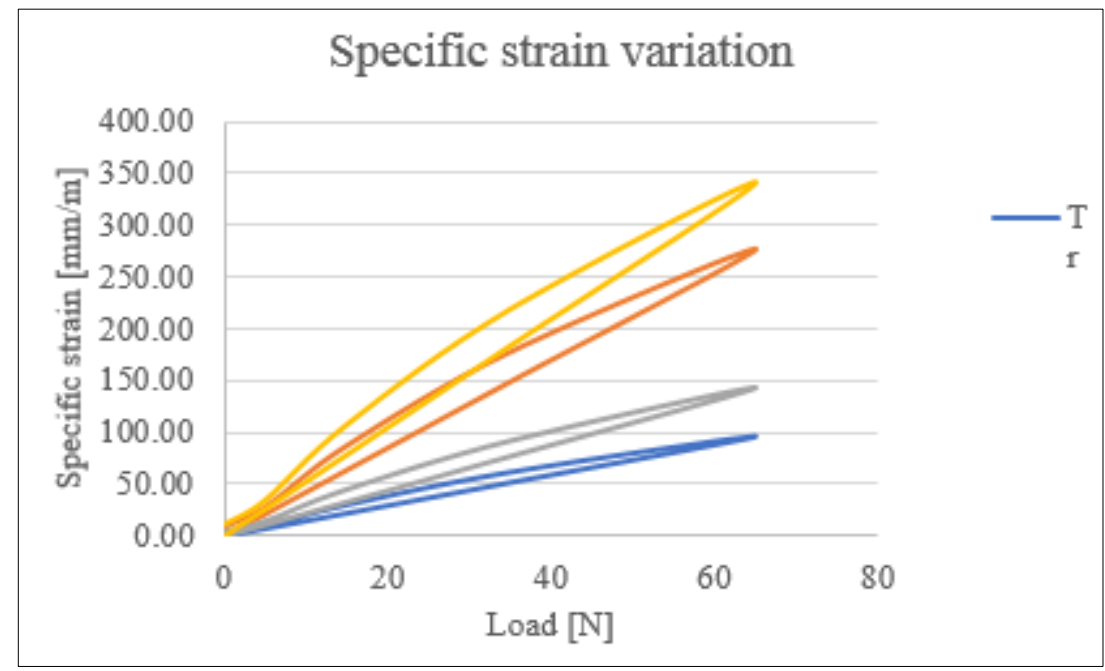

Figure 25. Specific strain variation

3. Analysing the results obtained for the reinforced plane plate panel, the level of deviation between experiment and numerical analysis is also acceptable (Table 8).

Table 8. Reinforced plane plate panel - under $65 \mathrm{~N}$ load

\begin{tabular}{|c|c|c|c|c|c|}
\hline Load & $\operatorname{Tr} \mathbf{1}(\mathbf{O x})$ & $\operatorname{Tr} \mathbf{2}(\mathbf{O x})$ & $\operatorname{Tr} \mathbf{3}$ & $\operatorname{Tr} \mathbf{4}$ & $\operatorname{Tr} \mathbf{5}(\mathbf{O x})$ \\
\hline Normal Stress & $5.03 \%$ & $3.48 \%$ & $3.35 \%$ & $3.06 \%$ & $6.01 \%$ \\
\hline
\end{tabular}

4. The comparative analysis performed for the stress level obtained experimentally and numerically for the free plane plate panel $(\operatorname{Tr} 2,4-O x)$ in Table 2, and respectively the reinforced plane plate panel $(\operatorname{Tr} 1,2-O x)$ in Table 4, is highlighted in Table 9 and Figure 26. It can be easily shown that the presence of the reinforcements on the two main directions, has a significant impact on the reduction of stress values, in some cases with $300 \%$. These significant improvements lead to the conclusion that 
impact areas (bow areas of leisure boats) must be designed with reinforced plane plate panels to reduce the risk of damage.

Table 9. Comparison between measured and calculated normal stress

\begin{tabular}{|c|c|c|c|c|}
\hline \multicolumn{5}{|c|}{ Panel without stiffeners (pos "1" on the graph) } \\
\hline $\begin{array}{l}\text { Load } \\
{[\mathrm{N}]}\end{array}$ & Item & Transducer & $\operatorname{Tr} 2(O x)$ & $\operatorname{Tr} 4(0 x)$ \\
\hline \multirow{2}{*}{65} & 1 & Normal stress measured $[\mathrm{Pa}]$ & $5.24 \mathrm{E}+06$ & $6.41 \mathrm{E}+06$ \\
\hline & 2 & Normal stress calculated $[\mathrm{Pa}]$ & $5.40 \mathrm{E}+06$ & $6.80 \mathrm{E}+06$ \\
\hline \multicolumn{5}{|c|}{ Panel with stiffeners (pos "2" on the graph) } \\
\hline $\begin{array}{l}\text { Load } \\
{[\mathrm{N}]}\end{array}$ & Item & Transducer & $\operatorname{Tr} 1(O x)$ & $\operatorname{Tr} 2(0 x)$ \\
\hline \multirow{2}{*}{65} & 3 & Normal stress measured $[\mathrm{Pa}]$ & $1.80 \mathrm{E}+06$ & $2.20 \mathrm{E}+06$ \\
\hline & 4 & Normal stress calculated $[\mathrm{Pa}]$ & $1.89 \mathrm{E}+06$ & $2.28 \mathrm{E}+06$ \\
\hline \multirow{2}{*}{\multicolumn{2}{|c|}{ Difference }} & Item $1 /$ Item 3 & $291.11 \%$ & $291.36 \%$ \\
\hline & & Item 2 / Item 4 & $285.71 \%$ & $298.25 \%$ \\
\hline
\end{tabular}

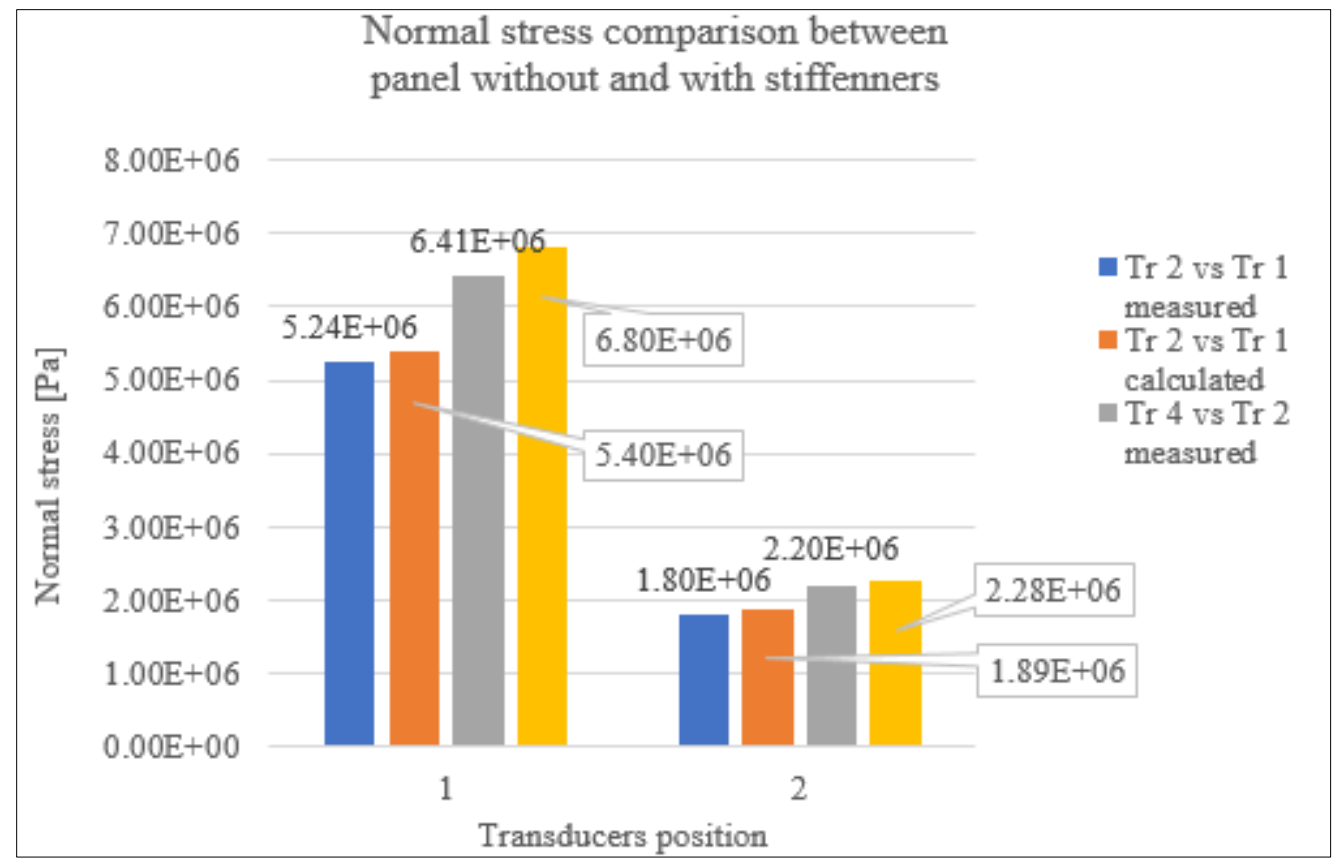

Figure 26. Comparison between panel without and with stiffeners

\subsection{Dynamic analysis for the free and reinforced GRP panel}

The study of the dynamic behaviour of the free and reinforced GRP plane plate panels has revealed a multitude of valuable pieces of information regarding the correct setup and procedure required for the study of GRP plates. The results obtained show that:

1. In Table 10, the centralized displacements indicate that in the case of the reinforced panel, the experimental results (depending on the impact force) are reduced by $202.91 \%$ and $147.25 \%$.

2. Same as above, the same comparison can be made for the numerical results obtained, where the difference between the two analysed panels is similar to the experimental values, $205 \%$ and $145 \%$.

3. The experiment has also supplied images which are a proof of small manufacturing defects that results in shaded area during the optical system measurement process. The system is able to detect small differences in thickness between layers in the case of composite materials. 
Table 10. Influence of stiffeners on the maximum impact displacement

\begin{tabular}{|c|c|c|c|}
\hline \multicolumn{4}{|c|}{ Maximum displacement measured [mm] } \\
\hline & \multicolumn{2}{|c|}{ Panel type } & Difference \\
\hline Load [N] & $\begin{array}{c}\text { Without } \\
\text { stiffeners }\end{array}$ & With stiffeners & Without / With \\
\hline 9.04 & 7.67 & 3.78 & $202.91 \%$ \\
\hline 18.08 & 13.4 & 9.1 & $147.25 \%$ \\
\hline \multicolumn{4}{|c|}{ Panel type } \\
\hline \multicolumn{4}{|c|}{ Maximum displacement calculated [mm] } \\
\hline Load [N] & $\begin{array}{c}\text { Without } \\
\text { stiffeners }\end{array}$ & With stiffeners & Without / With \\
\hline 9.04 & 8.12 & 3.95 & $205.57 \%$ \\
\hline 18.08 & 14.2 & 9.75 & $145.64 \%$ \\
\hline
\end{tabular}

\section{Conclusions}

The results obtained during the numerical analysis are validated by the results obtained via the experimental method. More than that, it proves that the method applies successfully to GRP panels.

The recorded level of deviation between the numerical and the experimental method is within $10 \%$, which is a deviation accepted by the mechanical engineering norms.

The numerical and experimental method applied can be successfully used in any mechanical research laboratory that is well equipped and performs these types of analyses on various structures [4].

The experimental setup and hardware required does not have a high cost of acquisition and it can be purchased easily.

Regarding the dynamic numerical modelling and experiment, one aspect is of utmost interest, the impact behaviour of GRP panels. This aspect has not been extensively researched, and the present study successfully brings some light on understanding what needs to be done in extenso. Similarly, to the static analysis, the results obtained numerically are validated experimentally using the optical system, Aramis HS. This system can be also employed during several similar studies, such as crack propagation for different materials and especially for GRP which is still an uncharted territory left for future studies and work.

\section{References}

1.HADĂR, A., Structuri din compozite stratificate, Editura Academiei Romane, Bucuresti, 2002.

2.TONG, L., MOURITZ, A.P., BANNISTER, M.K., 3D Fibre Reinforced Polymer Composites, Elsevier Science Ltd, Londra, 2002.

3.GARDINER, G., Removing the barriers to light weighting ships with composites, https://www.compositesworld.com/articles/removing-barriers-to-lightweighting-ships-withcomposites.

4. JURADO, A., KRAUSE, M., PABOEUF, S., Towards Safety of Composite Ships, 2019, https://www.ramsses-project.eu/fileadmin/Download/Presentations/IMO_SDC7_-

Towards_Safe_Composite_Ships_by_FIBRESHIP_and_RAMSSES_project-_rev9.pdf.

5. CHAWLA, K., Composite material: Science and Engineering, Fourth Edition, Switzerland: Springer International Publishing, 2019 https://doi.org/10.1007/978-3-030-28983-6.

6. BASEM, T., Use of Composites as Alternative Materials in Ship Structures, Alexandria University, Egipt, 2016.

7. JONES, R., M., Mechanics of composites materials, Second edition, Taylor\&Francis, 1999.

8. CRAWFORD, R., J., MARTIN, P., J., Plastics Engineering $-4^{\text {th }}$ Edition ”, $4^{\text {th }}$ ed. Elsevier, 2020 , https://doi.org/10.1016/C2015-0-0050-0

9. GIBSON, R., F., Principles of Composites Material Mechanics, CRC Press, 2016, https://doi.org/10.1201/b19626. 
10. ABRATE, S., Impact on composite structures, Cambridge University Press, Cambridge, UK, 1998. 11. MOURITZ, A., P., GELLERT, E., BURCHILL, P., CHALLIS, K., Review of advanced composite structures for naval ships and submarines, Composites Structures, 53 (1), 2001, 21-42, https://doi.org/10.1016/S0263-8223(00)00175-6.

12.***Spider8, User Manual, https://www.hbm.com/en/2290/catman-data-acquisition-software/. 13. ***CosmosM, User Manual.

14.RADES, M., Metode dinamice pentru indentificarea sistemelor mecanice, Editura Academiei Republicii Socialiste Romania, Bucuresti, 1979.

15.***Aramis HS User Manual, GOM a Zeiss Company, https://www.gom.com/en/products/3dtesting/aramis-app.

Manuscript received: 19.11 .2021 